\title{
La soledad contemporánea desde la obra de pensadores esenciales: análisis y perspectivas
}

\author{
Contemporary loneliness from the work of essential thinkers: \\ analysis and perspectives \\ Lilia Leticia García Peña* \\ Universidad de Colima \\ ORCID: https://orcid.org/0000-0002-2386-3058 \\ DOI http://dx.doi.org/I0.28928/ri/862019/aot3/garciapenal
}

\section{Resumen}

La soledad es un fenómeno creciente en nuestras sociedades contemporáneas. Si bien se trata de un asunto humano inmemorial, en los tiempos actuales, marcados por un hiperconsumismo globalizado, ha alcanzado escalas sin precedentes en la historia cultural. Este trabajo recoge y discute las reflexiones de pensadores esenciales y representativos de los siglos xx y xxi en torno a la soledad contemporánea La metodología tiene una base epistemológica interdisciplinar, es cualitativa, panorámica y cronológica. Los resultados permiten identificar las aristas del problema, así como los elementos del cambio sociocultural implicados. Los hallazgos pueden resultar provechosos para estudiosos de las diversas disciplinas sociales y humanas.

Palabras clave: soledad, siglo $\mathrm{xx}$, siglo $\mathrm{xxI}$, sociedades actuales, cambio sociocultural

\begin{abstract}
Loneliness is a growing phenomenon in our contemporary societies. Although loneliness is an immemorial human topic, in the current times, marked by a globalized hyper-consumerism, it has reached unprecedented scales in cultural history. This work collects and discusses the reflections on the theme of essential and representative thinkers of the 2oth and 2ist centuries around contemporary solitude. The methodology has an interdisciplinary epistemological base, it is qualitative, panoramic and chronological. The results allow to identify the edges of the problem as well as the elements of sociocultural change involved. The findings can be useful for scholars of the various social and human disciplines.

Key words‡ Solitude, xx Century, xxi Century, Current Societies, Sociocultural Change
\end{abstract}

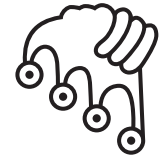

IZTAPALAPA

Agua sobre lajas

*1lgarcia@ucol.mx 


\section{Introducción}

L a soledad es un fenómeno creciente en nuestras sociedades contemporáneas. No me refiero a aquella que enriquece y dignifica al ser, sino a la que lo disminuye y margina de procesos sociales fundamentales y que, en una palabra, lo deshumaniza. Visto en cualquiera de sus dimensiones y facetas, este aspecto humano inmemorial, marcado actualmente por un hiperconsumismo globalizado, muestra hoy escalas sin precedentes en la historia cultural.

Al estudiar y analizar la condición humana desde la perspectiva de pensadores fundamentales: filósofos, escritores, psicólogos sociales, sociólogos, historiadores de las ideas y antropólogos, llama poderosamente la atención el hecho de que todos ellos, desde principios del siglo $\mathrm{xx}$ hasta nuestros días, aborden como un asunto central la problemática de la soledad contemporánea, lo cual confirma la pertinencia de esta reflexión.Me propongo entonces mostrar y discutir aquí los planteamientos de estos pensadores contemporáneos que nos acercan de manera sistemática, creativa y holística a la soledad como particularidad de nuestra época.

Los autores elegidos provienen de distintas áreas: desde la filosofía hasta la antropología. Se incluyen aquellos cuya vida y obra atraviesan el siglo xx. Como todo conocimiento es parcial y limitado, es probable la ausencia de algún autor relevante, pero todos los incluidos son, si duda, imprescindibles para pensar nuestra contemporaneidad. Es muy importante subrayar que solo he seleccionado pensadores que tratan el tema de la soledad contemporánea como resultado de los procesos históricos, económicos y sociales que conducen a la llamada posmodernidad, modernidad tardía o modernidad líquida en las sociedades occidentales contemporáneas; no contemplo a teóricos del siglo xx que tratan el tema como fenómeno psicológico o existencial. La perspectiva metodológica es interdisciplinar y cualitativa. He optado por la riqueza panorámica que ofrece la integración de voces, variadas y diversas, de aquellos autores que enriquecen la teoría social contemporánea y contribuyen a la comprensión del problema que nos ocupa desde diversos ángulos. Los planteamien- 
tos que se recogen y discuten siguen un orden cronológico a fin de poder advertir la dinámica de cambio sociocultural del asunto que abordamos:

I. "El suicidio" de Durkheim y "El extranjero" de Simmel: la reflexión sobre la soledad contemporánea en el temprano siglo xx; 2. "La muchedumbre solitaria" de David Riesman; 3."La soledad secuestrada" de Michel Foucault; 4."El ocaso de los afectos" de Fredric Jameson; 5. "La experiencia secuestrada" de Anthony Giddens; 6. "La soledad vacía" de Lipovetsky; 7."La soledad electrónica" de Roman Gubern; 8. "La soledad postorgánica" de Paula Sibilia y 9. "La soledad masificada" de Zygmunt Bauman .

\section{"El suicidio" de Durkheim y "El extranjero" de Simmel; la reflexión sobre la soledad contemporánea en el temprano siglo $\mathrm{xx}$}

Durkheim y Simmel se preocuparon como todos los teóricos sociales clásicos por el mundo moderno y sus perspectivas y, aunque subrayaron las ventajas de la modernidad, emprendieron a la vez una crítica de los problemas que vislumbraban. Émile Durkheim (Francia I858-I917) plantea en su estudio El suicidio (1897) una de las primeras reflexiones en torno a la soledad como condición social significativa en el siglo xx. El suicidio es, desde luego, la más definitiva expresión de la soledad humana. Al preocuparse por vincular los comportamientos individuales con causas sociales, este autor mostró de manera colateral que la soledad era ya un asunto social relevante:

Lo que prueba el número excepcionalmente elevado de las muertes voluntarias es el estado de perturbación profunda que sufre las comunidades civilizadas y atestigua su gravedad. Hasta se puede decir que nos da su medida. Cuando estos sufrimientos se expresan por boca de un teórico, se puede creer que son exagerados e infielmente traducidos. Pero aquí, en la estadística de los suicidios, vienen como a registrarse por sí mismos sin dar lugar a la apreciación personal. No se puede, pues, contener esa corriente de tristeza colectiva, más que atenuando, a lo menos, la enfermedad general de que es el resultado y el signo (Durkheim, 2004ः 343).

Desde I893 Durkheim introduce en La división del trabajo social la noción de'anomia' como la carencia de un soporte y regulación suficientes que integren al individuo; en "El suicidio" la vincula de modo determinante a la experiencia límite de la soledad 
y la autodestrucción: "La anomia es, pues, en nuestras sociedades modernas, un factor regular y especifico de suicidios" (2004: 222).

Georg Simmel (I858-1918), filósofo alemán que contribuyó a delimitar el campo epistemológico de la sociología, "considerado un sociólogo de la modernidad" (Dettano, 2013: 88), influyó en la Escuela de Chicago y en su teoría central: el interaccionismo simbólico.

Escribió “La metrópolis y la vida mental" en 1903 y fue uno de los grandes pensadores urbanos. Se centró en el nuevo individuo que va surgiendo en el particular ambiente moderno y vertiginoso de las grandes ciudades y percibió que la vivencia de soledad es más definitiva en el entorno de la multitud metropolitana. Para Simmel "la despersonalización y el aislamiento de la personalidad se producen cuando se disuelven los vínculos naturales de adscripción, es decir, la comunidad. Sin negar que esta situación pueda ser riesgosa, el autor propone una visión más optimista al respecto: es la disolución de estos vínculos naturales la que amplía de forma significativa los márgenes de la libertad individual" (Rizo, 2006: 50).

Simmel analizó al extranjero como un tipo. Su ensayo sobre el tema está incluido en el capítulo 9 de Sociología. Estudios sobre las formas de socialización (Berlín, 1908). Trabajamos aquí con su reproducción en Simmel (20I2), con traducción de Javier Eraso Ceballos. El extranjero "no es el nómada que llega hoy y parte mañana, sino el que llega hoy y mañana se queda; o por así decir, el emigrante potencial, que, aunque se haya detenido, aún no ha superado la ausencia de vínculo propia del ir y venir" (Simmel, 20I2: 2I). El extranjero se ubica en un espacio al que no pertenece desde siempre y lleva consigo cualidades de otros espacios; se vinculan en la misma figura lo cercano y lo lejano, lo que pertenece y lo que es ajeno: "es un elemento del grupo, como también lo son los pobres y los distintos énemigos interiores'. Es un elemento cuya posición supone al mismo tiempo exterioridad y confrontación" (Simmel, 20I2: 2I). La condición de extranjero en términos de relaciones humanas lo mismo supone, según Simmel, comunidad e interacción como, en forma simultánea, distanciamiento y repulsión. El filósofo alemán explica que el extranjero, por definición, no posee tierras "ya sea en su sentido físico, como en el figurado" (Simmel, 2012: 22). Es una persona móvil que pone en contacto lo distante y lo próximo, establece interacción con el grupo pero no está nunca orgánicamente ligado.

Simmel observa una cualidad positiva en la condición de extranjero: su diferencia con respecto al grupo lo define también en términos de libertad y lo dota de la posibilidad de distancia crítica, como si viera -dice- desde lo alto. Al mismo tiempo, esta libertad"alberga, no obstante, potenciales peligros" (Simmel, 20I2: 23): 
El extranjero nos resulta próximo en la medida en que sentimos que compartimos con él una misma naturaleza nacional, social, profesional o genéricamente humana. Pero también nos resulta distante en la medida en que esos mismos rasgos no pertenecen solo a él y a nosotros sino que son propios de muchas más personas (Simmel, $2012 \div 24)$.

Desde esa perspectiva, ser extranjero no significa necesariamente venir de otro país. La dinámica de ser extranjero en términos de vínculos humanos es más amplia; también supone que las personas pueden sentirse extrañas en su propia tierra o en los entornos sociales a los que desean pertenecer. "En ese sentido, la dimensión de lo extranjero se desliza incluso en las relaciones más íntimas" (Simmel, 2012:24). Ser extranjero entraña la problematización de la relación con aquel con quien se pretende establecer y experimentar la cercanía, la armonía y la similitud. Significa conciencia del ser en soledad y diferencia; el reconocimiento, no resuelto, con los otros a partir de lo próximo y lo diverso.

\section{"La muchedumbre solitaria" de David Riesman (1909-2002)}

La excelente y visionaria obra del sociólogo y psicólogo estadounidense David Riesman (1909-2002): La muchedumbre solitaria, fue escrita entre 1948 y 1949. En ella se propuso estudiar los tipos de carácter social y sus procesos de gestación y transformación en el seno de la clase media urbana (Riesman, 1964: 78). Define primeramente el carácter como "la organización más o menos permanente, social e históricamente condicionada, de los impulsos y satisfacciones de un individuo, la clase de 'equipo' con que enfrenta al mundo y la gente” (Riesman, 1964: 16). La metáfora de la soledad contemporánea que Riesman elabora es precisamente la que da título a su obra: "La muchedumbre solitaria". Veamos su planteamiento. Riesman distinguió tres tipos fundamentales de carácter social:

a) Dirigido por la tradición‡ en este tipo la persona "prácticamente no piensa en sí misma como en un individuo. Menos aún se le ocurre que podría determinar su propio destino en términos de metas personales y a largo plazo o que el destino de sus hijos pueda no ser el del grupo familiar" (Riesman, 1964:28).

b) Dirección interna‡ en este tipo el individuo es dotado desde la más temprana infancia por los adultos: padres, maestros, autoridades con mecanismos y estrategias que pretenden habilitarlo para funcionar en el grupo a partir de sí mismo. 
La persona dirigida desde adentro ha incorporado tempranamente un giroscopio psíquico que sus padres ponen en movimiento y que, más adelante, puede recibir señales de otras autoridades que se asemejan a sus padres. Se mueve en la vida con menos independencia de lo que parece, obedeciendo a este piloto interno. El apartarse del rumbo fijado, sea en respuesta a impulsos internos o a las voces fluctuantes de sus contemporáneos, puede conducir al sentimiento de culpa (Riesman, 1964: 34).

El destino de los sujetos de dirección interna suele desenvolverse con independencia de los otros, pero con la huella de soledad en los espacios en que desarrolla su ejercicio social: el hogar, la escuela, etc. Sin embargo,

Vemos que en una sociedad que valora la dirección interna, la soledad y la persecución no se consideran el peor de los destinos [... ] Si bien los adultos rara vez intervienen para guiar y ayudar al niño, tampoco le dicen que debe formar parte de una muchedumbre y divertirse (Riesman, 1964: 77).

Es decir, este carácter social privilegia la consolidación de la personalidad propia más allá de sus costos en función de la falta de interacción con los otros.

c) Dirigido por los otros: el carácter "dirigido por los otros" es el que interesa para la metáfora de la soledad contemporánea en cuestión. Según Riesman, este tipo de carácter parece haber surgido durante los últimos años en la clase media alta de las ciudades grandes y resulta sorprendentemente similar al del estadounidense. Precisa que su análisis del carácter dirigido por los otros es entonces:

al mismo tiempo, un análisis del norteamericano y del hombre contemporáneo [...] como hipótesis me inclino a pensar que el tipo dirigido por los otros se encuentra en los Estados Unidos más cómodo que en ninguna otra parte [...] En contraste, también me inclino a atribuir mayor influencia al capitalismo, el industrialismo y la urbanización, todas tendencias internacionales, que a cualquier otra peculiaridad formativa del carácter en la escena estadounidense (Riesman, 1964:30).

Para el tipo de carácter social dirigido por los otros, son sus contemporáneos quienes constituyen la fuente de dirección para el individuo, sea los que conoce o aquellos con quienes tiene una relación indirecta, a través de amigos y de los medios masivos de comunicación. Tal fuente es, desde luego, "internalizada", en el sentido de que la 
dependencia con respecto a ella para una orientación en la vida se implanta desde temprano (Riesman, 1964:32).

El tipo social dirigido por los otros, que Riesman ve ya cristalizado en la primera mitad del siglo $\mathrm{xx}$, muestra una insaciable

"necesidad psicológica de aprobación” (1964\$32) por parte del grupo. El autor explica que mientras que el tipo social dirigido por la tradición se atiene al impacto de la cultura y el tipo de dirección interna se afianza en cierta insensibilidad hacia los demás, la persona dirigida por los otros busca y es capaz"de una intimidad rápida, aunque a veces superficial, con todos" ( Riesman, 1964:35).

Aunque, desde luego, plantea su análisis en términos dinámicos y con fronteras permeables entre los tipos, el que corresponde a la "Muchedumbre solitaria" es este tercer tipo que, según su estudio, fue consolidándose hacia los años cincuenta. El individuo se moverá entre la multitud tratando de captar y satisfacer las señales de los otros y generará una ansiedad difusa, constante y creciente. Sea estudiante, maestro, padre, hijo, adulto, joven, hombre o mujer, homosexual o heterosexual,"todo el poder, y no solamente una parte del él, está en las manos del grupo aprobador real o imaginario" (Riesman, 1964:57).

Este tipo tiene mucho que ver con las sociedades consumistas, en que la persona es una mercancía y al mismo tiempo pierde su individualidad para extraviarse en una masa anónima de consumidores potenciales; produce seres estandarizados que se adhieren al grupo buscando suprimir toda diferencia. Y el resultado no es, sin embargo, la comunicación, la compañía y la solidaridad, sino la multitud agonizante: "La muchedumbre solitaria".

\section{"La soledad secuestrada" de Michel Foucault}

Michel Foucault (1926-I984) es el gran teórico del poder. Y al hablar del ejercicio del poder necesariamente bordeamos el problema de las soledades. No hay poder que no se acompañe de la violencia asociada con la marginación y la exclusión, cuyo efecto se multiplica en numerosos individuos, y que en sus últimas consecuencias se viven siempre en soledad. Foucault escribe: "Las tres figuras que constituyen el ámbito de la anomalía: el monstruo humano, el individuo a corregir, el niño masturbador" (2007: 6I); en la obra de este autor se puede ver una red importante de metáforas 
que representan a los individuos segregados, diferentes, sobre los que se ejerce el poder mediante el cual son disciplinados. Las personas "diferentes" son vistas en el espacio biopolítico que aloja los mecanismos y las estrategias normalizadoras en el cuerpo mismo como: "Los anormales","El monstruo," El cuerpo deforme”,"El loco". El individuo sufre una soledad disciplinada, es lanzado a una zona de negación hasta que internaliza las normas de sujeción que la red de poder diseña y queda convertido en un "sujeto" disciplinado.

En el ejercicio de la disciplina y la autodisciplina del sujeto, es decir, en el proceso de gestación de las que Foucault llama "Las tecnologías del yo", el filósofo francés destaca dos metáforas referentes a las actividades de vigilancia y castigo:

el vigía, que no admite a nadie en la ciudad si esa persona no puede demostrar quién es (debe ser un "vigilante" del flujo del pensamiento) y el cambista, que comprueba la autenticidad de la moneda, la mira, la pesa y la verifica. Debemos ser cambistas de nuestras representaciones de los pensamientos, examinándolas con atención, verificándolas, comprobando su metal, su peso, su efigie (Foucault, 1990: 79).

Foucault logra demostrar que en nuestras sociedades contemporáneas las relaciones de poder pueden penetrar materialmente en el espesor mismo de los cuerpos, que existe "una red de bio-poder, de somato-poder" (Foucault, 1979: 156).

Todos estos planteamientos de Foucault expresados en nociones metafóricas son indiscutiblemente brillantes, pero quiero subrayar su expresión de "Soledad secuestrada", inmersa en el capítulo medular "El panoptismo" de su obra Vigilar y castigar:

La multitud, masa compacta, lugar de intercambios múltiples, individualidades que se funden, efecto colectivo, se anula en beneficio de una colección de individualidades separadas. Desde el punto de vista del guardián está reemplazada por una multiplicidad enumerable y controlada; desde el punto de vista de los detenidos, por una soledad secuestrada y observada (Foucault, 1998: 204. Las cursivas son mías).

En el entorno de una sociedad vigilante y castigadora, en la que se tienden las redes de un poder anónimo que está en todas partes y en ninguna, una sociedad esencialmente inquisidora, el individuo frágil, incapaz de ver y visto siempre, es arrojado a una soledad secuestrada por un poder omnipresente.

Es importante añadir que Foucault sabía que las sociedades disciplinarias no eran eternas, que transitarían a otras formas de sujeción. Deleuze, el gran lector de Foucault, complementó su pensamiento explicando en 1994, en su ensayo "Posdata 
sobre las sociedades de control", que Foucault situó el origen de las sociedades disciplinarias en los siglos XVIII y xIX y que estas alcanzan su apogeo a principios del xx. Corresponden, recuerda, a la organización de los grandes espacios de encierro para los cuales, como el maestro demostró, la prisión sirve de modelo analógico. Pero Deleuze permite apreciar que las disciplinas sufren una crisis durante los últimos años y los muros de los espacios cerrados y vigilados caen, favoreciendo y demandando nuevas fuerzas de control que se van instalando lentamente. Así, Deleuze señala que el esquema de Foucault sigue siendo, desde luego, vigente para comprender el comportamiento del poder, pero que vivimos una crisis generalizada de todos los lugares de encierro: prisión, hospital, fábrica, escuela, familia. De tal modo que "las sociedades de control [...] están reemplazando a las sociedades disciplinarias" (Deleuze, 2005: 117). Las estrategias disciplinarias advertidas por Foucault han mutado en controles cifrados: "El lenguaje numérico del control está hecho de cifras, que marcan el acceso a la información, o el rechazo. Ya no nos encontramos ante el par masa-individuo. Los individuos se han convertido en 'dividuos', y las masas, en muestras, datos, mercados o bancos" (Deleuze, 2005: II 8). El ser humano, dice Deleuze, ya no es el hombre encerrado por el poder sino controlado por el dinero "el hombre endeudado" (Deleuze, 2005ः I20). Diríamos, pues, con Deleuze, con base en el enorme aporte de Michel Foucault a la crítica del poder en nuestras sociedades, que la soledad contemporánea transita de una soledad secuestrada a una soledad también secuestrada pero ahora controlada y endeudada."Pero un día, quizás, el siglo será deleuziano" dijo alguna vez Foucault, y lo fue.

\section{"El ocaso de los afectos" de Fredric Jameson}

El reconocido crítico estadounidense de la cultura contemporánea Fredric Jameson (1934) se dedica al análisis literario y cultural desde una perspectiva marxista. Estudia básicamente las relaciones entre el desarrollo del capitalismo y la producción cultural; las formas estéticas posmodernas que coinciden con la mundialización de mercado. Para Jameson, la sociedad posmoderna está compuesta por cinco elementos básicos: capitalismo tardío, falta de profundidad, desvanecimiento de las emociones, supresión de la historicidad y tecnologías reproductivas. En 1984 publica su importante ensayo: El posmodernismo o la lógica cultural del capitalismo avanzado. Parte de analizar y poner en relación dos obras pictóricas: "Las botas" de Van Gogh y "Zapatos de polvo de diamante" de Andy Warhol. En la pintura de Van Gogh, una de las obras canónicas del modernismo en las artes visuales, se observan unos 
zapatos de campesino que hacen referencia, según destaca su análisis, a la miseria agrícola y la desolada pobreza rural; también a la transformación violenta del mundo campesino ante la nueva división del trabajo en el seno del capital. En ellos vibra también "el mundo ausente y la tierra revelándose a su alrededor junto con las pisadas fatigosas de la labriega, la soledad de las sendas rurales, la cabaña en un claro y los rotos y desgastados útiles de labranza en los surcos y en el hogar" (Jameson, I99I: 26). El otro par de zapatos, el de Warhol, "ya no nos hablan, evidentemente, con la inmediatez del calzado de Van Gogh: en realidad, casi me atrevería a decir que no nos hablan en absoluto" (Jameson, I99I: 27). No hay lugar para el espectador. Encontramos un conjunto aleatorio de objetos sin vida, separados del mundo vital. En el mundo representado por Warhol, dice Jameson, a diferencia del mundo de Van Gogh, no se pueden recuperar los fragmentos, es un mundo cruzado por la mercantilización y el fetichismo, muestra el surgimiento de "un nuevo tipo de insipidez o falta de profundidad, un nuevo tipo de superficialidad en el sentido más literal" (Jameson, I99I: 29). Vemos entonces la mutación del mundo objetivo actual convertido en conjunto de textos y simulacros. Esta nueva sensibilidad contemporánea conduce a la metáfora creada por Jameson: “El ocaso de los afectos". Según este autor, las nuevas relaciones del individuo con el mundo y con otras personas no están propiamente carentes de sentimiento, emoción o subjetividad, pero sí hay una frivolidad y una superficialidad, y definitivamente una pérdida de afectividad que puede ser captada en la representación de la figura humana. En "El grito" de Edvard Munch se expresan de modo paradigmático la alienación del sujeto a través de la representación de la emoción proyectada en el grito como gesto desesperado; en cambio, ahora las representaciones de las identidades se desplazan a la ausencia de profundidad y a los esquemas vacíos.

Fredric Jameson creó la imagen de "El ocaso de los afectos" para expresar esta característica de las sociedades contemporáneas. No se refiere desde luego a la desaparición total de los sentimientos y emociones, pero sí a su contención. Nuestra contemporaneidad, afirma, pone fin al dilema y lo sustituye por uno nuevo: "el fin de la mónada o del yo burgués tiene por fuerza que implicar también el fin de las sicopatologías de este yo, o lo que he estado denominando hasta ahora el ocaso de los afectos" (Jameson, 1991: 39). Esto no significa que se esté totalmente desprovisto de sentimientos, "sino más bien que tales sentimientos -que sería mejor y más exacto denominar 'intensidades', son ahora impersonales y flotan libremente, tendiendo a organizarse en una peculiar euforia" (Jameson, 1991ः 39). Los afectos de la ansiedad y la alienación parecen haber sido desplazados por una especie de euforia en nuestros días: "El mundo pierde entonces por un momento su profundidad y amenaza 
con transformarse en una piel satinada, una ilusión estereoscópica, un tropel de imágenes cinematográficas sin densidad. Pero ¿̇se trata de una experiencia jubilosa o terrorífica?" (Jameson, I99I: 77). Una barrera supuestamente protectora aleja a la persona de sí misma y de los otros en una soledad condenada al "ocaso de los afectos".

\section{"La experiencia secuestrada" de Anthony Giddens}

Anthony Giddens (1938) es uno de los teóricos contemporáneos que creen que hay más continuidad que discontinuidad entre nuestro mundo y el mundo moderno; utiliza términos como modernidad radical, alta o tardía para señalar que, aunque no se trata de la misma sociedad que la que describieron los teóricos clásicos, existen líneas de continuidad. Puesto que Giddens se centra más en los aspectos micro del mundo actual, especialmente en el yo y sus transformaciones, es uno de los pensadores que más claramente enfocan la experiencia de soledad individual e íntima en el marco de las interacciones sociales.

Para Anthony Giddens, "La vida personal se ha convertido en un proyecto personal abierto, que crea nuevas demandas y nuevas ansiedades. Nuestra existencia interpersonal se ve transfigurada completamente, al involucrarnos en lo que llamaré 'experimentos sociales de cada día, a los que nos someten los cambios sociales más amplios" (Giddens, 1998: 8). En I99I Giddens publica su texto Modernidad e identidad del yo. El yo y la sociedad en la época contemporánea. El capítulo 5 lleva por título la metáfora que nos interesa: "La experiencia secuestrada" (Giddens, 1995: 185). En ese entorno social marcado por el vértigo, la inestabilidad y la incertidumbre social y psicológica, los individuos, señala Giddens, tienden actualmente a autoprotegerse en una soledad que garantice una supervivencia vital pese al costo emocional y afectivo que supone. Giddens no elabora una metáfora que estrictamente incluya el término soledad, pero sí lo contiene. Los individuos de las sociedades contemporáneas tendemos a "autosecuestramos" de todas aquellas experiencias afectivas que puedan vulnerar nuestra vida y poner en riesgo la seguridad de nuestra identidad:

Lo que puede ser descrito como "secuestro de la experiencia" es consecuencia de la ruptura aun más radical de las instituciones de la modernidad con la tradición y la creciente intrusión de sus sistemas de control sobre las "fronteras externas" preexistentes de la acción social. Su consecuencia es la disolución de las líneas generales de la ética y de la moral que se referían a la actividad social, a lo trascendental, a la naturaleza y a la reproducción. Estas se transmutan, en efecto, por seguridad, en la 
rutina que ofrece la vida social moderna. Cierto sentido de seguridad ontológica se deriva primariamente de la rutina misma (Giddens, I998: 106).

"El secuestro de la experiencia" es una especie de represión u olvido a través del cual el individuo rechaza en la vida cotidiana experiencias que aunque fundamentales tienden a ser evitadas. Según Giddens son cuatro los ámbitos del secuestro: la locura, la criminalidad, la enfermedad y la muerte, y la sexualidad y la naturaleza. El individuo tiende a aislarse de los otros, o a aislar aquello que lo amenaza. Evita el contacto con el demente, el criminal, el enfermo crónico y reemplaza el erotismo con sexualidad. La represión de estas cuestiones existenciales, si bien le asegura una tranquilidad inmediata, lo confina a la soledad, a la falta de empatía y de intensidad vital en el contacto con los otros.

El evitar todo riesgo y el "secuestro de la experiencia" provoca que prive una sensación de "aislamiento existencial" que "no es tanto una separación entre individuos cuanto un apartamiento de los recursos morales necesarios para vivir una existencia plena y satisfactoria" (Giddens, 1995: 18).

\section{"La soledad vacía" Lipovetsky}

La amplia obra del filósofo y sociólogo francés Gilles Lipovetsky (1944) llega hasta nuestros días. Su libro La era del vacío, publicado en 1983 , sigue impactando en la comprensión de los procesos de las sociedades de finales de siglo xx y del siglo xxI. En este volumen analiza el narcisismo social, el hiperconsumismo, la supresión de lo trágico en la era posmoderna. Como bien se sabe, la soledad física no necesariamente es indicio de aislamiento, pero es importante recordar que ya en 1983 Gilles Lipovetsky advertía una tendencia cada vez mayor a que las personas vivieran solas: "entre 1970 y 1978, el número de americanos entre catorce y treinta y cuatro años, que viven solos, fuera de cualquier situación familiar, se ha triplicado..." (Lipovetsky, 2000: 76). Múltiples estudios analizan por su parte cómo, por ejemplo, en América Latina esta tendencia ha presentado un incremento que se muestra en el mayor número "de los hogares unipersonales en el periodo de 1997 a 1999, debido a 'los procesos de individualización' propios de la Modernidad" (Uribe, 20I0: 58). Existe, entonces, un indiscutible aumento de personas que viven solas debido a factores sociales, económicos y culturales que han acompañado las grandes transformaciones de la globalización: divorcios, soltería elegida, jóvenes que prefieren viajar, mayor migración laboral y un mayor número de adultos en plenitud viudos o solos por 
haberse elevado su expectativa de vida en razón del aumento en la seguridad social y los avances en las áreas de salud. Esta condición de soledad que podría augurar mayor libertad y plenitud implica también una suerte de abandono y despojo social. Uno de los novelistas mexicanos actuales, J. M. Servín, nombra con mucha claridad esta forma de vivir cada vez más amplia en el título de una de sus novelas: Cuartos para gente sola (2003).

Para Lipovetsky, la soledad de finales del siglo XX es una soledad indiferente: "se ha convertido en un hecho, una banalidad al igual que los gestos cotidianos. Las conciencias ya no se definen por el desgarramiento recíproco; el reconocimiento, el sentimiento de incomunicabilidad, el conflicto, han dejado paso a la apatía y la propia intersubjetividad se encuentra abandonada" (2000: 47).

Aunque Lipovetsky no elabora propiamente la expresión "soledad vacía" al analizar las características de la sociedad actual, queda clara la indiferencia que surge entre las personas en una sociedad de masas, y la imagen de "vacío" que da título a su obra puede claramente calificar la soledad que experimentan los sujetos. Individuos que viven una soledad vacía en un mundo vacío en el que se anulan las contradicciones en función de un hedonismo obsesivo, en el que se invisibiliza al otro en función de un hiperindividualismo, en el que solo se vive el instante efímero.

Lipovestky subrayó en La era del vacío que:

Cuanto más la ciudad desarrolla posibilidades de encuentro, más solos se sienten los individuos; más libres, las relaciones se vuelven emancipadas de las viejas sujeciones, más rara es la posibilidad de encontrar una relación intensa. En todas partes encontramos la soledad, el vacío, la dificultad de sentir, de ser transportado fuera de sí: de ahí la huida hacia adelante en las "experiencias" que no hace más que traducir esa búsqueda de una "experiencia" emocional fuerte. ¿Por qué no puedo yo amar y vibrar? Desolación de Narciso, demasiado bien programado en absorción en sí mismo para que pueda afectarle el Otro, para salir de sí mismo, y sin embargo insuficientemente programado ya que todavía desea una relación afectiva (Lipovetsky, 2000: 78. Las negritas son mías).

Lipovestky habla de un narcisicismo colectivo: "nos juntamos porque nos parecemos, porque estamos directamente sensibilizados por los mismos objetivos existenciales. El narcisismo no solo se caracteriza por la autoabsorción hedonista sino también por la necesidad de reagruparse con seres 'idénticos'" (2000: 14). La noción de soledad vacía de Lipovetsky es entonces aún más problemática porque, como señala Tamés, 
el individualismo descrito por Lipovetsky a lo largo de las páginas de La era del vacío, no es de una naturaleza aislada, esférica. Es un narcisismo colectivo el que se está viviendo, en el sentido de que el discurso agrupa lo que está cerca, a la mano, lo que es similar o idéntico a uno mismo: ramificaciones de lo colectivo, intereses miniaturizados, grupos hiperespecializados; los círculos de interacción se contraen haciendo mini grupos, pero explotan en su diversidad (Lipovetsky, 2007: 48).

Las soledades vacías de Lipovetsky son grupos de solitarios o solitarios asociados por las mismas carencias, por lo similar.

\section{"La soledad electrónica" de Roman Gubern}

Roman Gubern (1934), especialista en cultura de la imagen y comunicación audiovisual, entre cuyos estudios se encuentran Historia del cine (1969), El lenguaje de los cómics (1972), Mensajes icónicos en la cultura de masas (1974), y que además publicó: El simio informatizado (1987), La mirada opulenta. Exploración de la iconosfera contemporánea (1987), Del bisonte a la realidad virtual (1996), en el siglo Xxi ha trabajado La imagen pornográfica y otras perversiones ópticas (2005) y Cultura audiovisual (2013).

En su obra El eros electrónico (2000) aborda los efectos emocionales generados por las nuevas tecnologías de información y comunicación en el ser humano como sujeto biocultural; estudia las implicaciones emocionales y afectivas de los nuevos medios en las sociedades posmodernas o posindustriales. Analiza el ocio electrónico, la cultura del espectáculo, el proyecto de la inteligencia artificial, el tema de los robots, humanoides y ciborgs, las emociones en la red, las estrategias del erotismo y los paraísos icónicos.

Lo que interesa subrayar aquí es que a lo largo de su obra Gubern advierte el problema de la soledad como una constante: la soledad en el interior de los automóviles en los largos y cotidianos trayectos urbanos, la recurrencia permanente de "ruido" que alivie la angustia y el miedo al silencio prototípico de nuestras sociedades. Habla incluso del "síndrome contemporáneo del miedo a la soledad" (Gubern, 2000: I7) y de una Era de la Soledad: "Paradójicamente, la era de la comunicación se ha revelado finalmente como la era de la soledad” (Gubern, 2000:219).

Este autor crea una imagen muy precisa para el fenómeno que estudia: "la soledad electrónica" (Gubern, 2000: I4). Hace referencia a que en I964 el publicista Ernst Dichter describió metafóricamente el hogar como una "cueva aterciopelada", espacio 
familiar en el que un ama de casa detenta el poder hegemónico auxiliada por aparatos electrodomésticos para el trabajo pesado que tienen connotaciones masculinas. De la cueva aterciopelada hemos pasado a la "cueva hogarótica" ya no aterciopelada sino electrónica y telematizada. La casa es un espacio cableado, parabolizado. Es un nicho electrónico en el que las personas se encierran como en un hogar-búnker, precisa Gubern, y ahí fluye el trabajo, el ocio, el devenir tecnológico y electrónico del ser. La casa ofrece una aparente autosuficiencia electrónica frente a la experiencia de una "comunidad sin proximidad física ni emocional que convierte a la sociedad en un desierto lleno de gente" (Gubern, 2000: 165).

"La soledad electrónica" surge en un entorno impactado por las modernas tecnologías de comunicación e información que están modificando la vida de las personas arrojándolas al biosedentarismo físico, intelectual y emocional. El actual "homo informaticus" (Gubern, 2000: 8) vive un protagonismo tecnológico inserto en una cultura claustrofílica y paga un precio emocional con una vida de pobre nivel social, cultural. Los seres encerrados en la aparente seguridad y confortabilidad del hogar, no resuelven las necesidades vitales básicas y viven las consecuencias de la nueva soledad electrónica.

\section{"La soledad postorgánica" de Paula Sibilia}

La antropóloga argentina Paula Sibilia (1967) publicó en 2005 El hombre postorgánico. Cuerpo, subjetividad y tecnologías digitales. Centra su investigación en el estatuto del cuerpo y de sus imágenes, de las nuevas prácticas corporales y de las transformaciones en la subjetividad contemporánea. Debo decir que Sibilia no incluye en forma explícita el término soledad, pero sí construye la noción metafórica de una condición postorgánica del ser humano actual. El hombre postorgánico es aquel moldeado por las dos grandes revoluciones actuales: la informática y la biotecnológica, que convierte el cuerpo humano en un sistema de información genética procesable que impacta en un nuevo orden biológico, social y cultural, todo esto en el marco del capitalismo industrial y consumista. Según Sibilia, los cuerpos y las almas son "bioprogramados" y "formateados" aceleradamente (Sibilia, 2005: 158), "mientras se va esfumando la metáfora del hombre-máquina que motorizaba el arsenal de la tecnociencia prometeica y cede su lugar al modelo del hombre-información" (Sibilia, 2005: 96). La ética capitalista fundamentada en el principio de "El tiempo es dinero" sigue siendo la misma, pero el tiempo del hombre postorgánico ha pasado de ser analógico a un continuo digital y ondulante. Eso explica, dice Sibilia, que Deleuze 
haya elegido a la serpiente como el animal más representativo de las sociedades de control y que, del mismo modo, el sistema nervioso y el código genético sean metáforas privilegiadas hoy en día (Sibilia, 2005: 260).

El espacio humano del hombre postorgánico es básicamente virtual: "La tecnología continuará migrando hacia el cuerpo, reconfigurándolo, expandiéndolo y transportándolo hacia lugares remotos en tiempo real. El próximo siglo, más y más personas van a vivir, interactuar y trabajar entre mundos interiores y exteriores a la computadora" (Kac en Sibilia, 2005: 62). En la sociedad actual las barreras espaciales son derribadas por los dispositivos y servicios teleinformáticos; ser es estar conectado: "a medida que interactúo con la Red, me reconfiguro a mí mismo; mi extensión-red me define exactamente como mi cuerpo material me definía en la vieja cultura biológica; no tengo ni peso ni dimensión en cualquier sentido exacto, solo me mido en función de mi conectividad" (Ascott en Sibilia, 2005: 63).

Si en las sociedades contemporáneas la realidad cambia y se reformula de acuerdo con los parámetros de la biotecnología y la informática, los fundamentos del biopoder planteado y estudiado por Michel Foucault no solo no desaparecen, sino que se ven reforzados: "vemos cómo emerge toda una mística ligada a los genes, que parece capaz de convertir a esos componentes moleculares de los organismos humanos en los nuevos protagonistas del biopoder" (Sibilia, 2005: 23I).

La soledad postorgánica es la que olvida la dimensión humana del cuerpo, la necesidad de la proximidad de los seres, la comunicación que solo surge entre lo más plenamente humano más allá de cifras y datos. Las personas aturdidas y exhaustas por intercambios veloces y superficiales apenas tienen tiempo y espacio para una auténtica intimidad consigo mismas y con los otros. La soledad postorgánica es también aquella que resulta de un mundo más violentamente desigual y excluyente. Los seres desechables, los parias de la modernidad diría Bauman, son arrojados furiosamente a los márgenes, solos y desprotegidos: "De modo que, lejos de menguar sus efectos, la virulencia de los dispositivos de exclusión socioeconómica está en aumento" (Sibilia, 2005:40). Es por ello que algunos sociólogos de tradición marxista, como Robert Kurz, se refieren a la etapa actual del capitalismo como "imperialismo de exclusión" (Sibilia, 2005:228). La soledad postorgánica es entonces la soledad de una sociedad cifrada e injusta. 


\section{"La soledad masificada" de Zygmunt Bauman}

El filósofo y sociólogo polaco Zygmunt Bauman (1925-2017) forjó a lo largo de los años su metáfora de "liquidez" para comprender y explicar las sociedades actuales, en función de su inmediatez y falta de soportes duraderos e inmarcesibles. Así lo vemos en los títulos de sus obras: Modernidad líquida, Vida líquida, Miedo líquido, Tiempos líquidos y Amor líquido, aludiendo este último a la franca fragilidad de los vínculos humanos de nuestra era. De modo que la metáfora de la soledad de Bauman bien pudiera haber sido "soledad líquida"; sin embargo, he preferido tomar otra expresión, la que da título a uno de sus más extraordinarios y contundentes escritos: La carta número 2 de su obra 44 cartas desde el mundo líquido: "Soledad masificada".

En esta breve carta Bauman condensa la esencia de la soledad contemporánea; es una imagen que suma los procesos, fenómenos y sentimientos que hemos tratado en todas las demás; yo diría que es una imagen que engloba los ángulos y matices que los distintos pensadores han subrayado. Este poder globalizador se debe al alcance del pensamiento de Bauman, pero también a que a él le toca ser testigo de eventos que abarcan todo el siglo xx y hasta bien entrado el xxI, lo cual le permite sumar y apreciar un panorama más total.

Bauman comienza evocando la experiencia de una adolescente cuya vida cotidiana corría totalmente sumergida en la Red, en un flujo incesante de contactos superficiales; una pérdida constante de intimidad y un cúmulo de intercambios demandantes y vanos.

Las personas parecen necesitar compulsivamente los estímulos visuales y auditivos de las pantallas y los dispositivos electrónicos. La posibilidad de quedarse solo aterra y se vive como una amenaza desagradable. Pero Bauman precisa que la causa no son los artilugios electrónicos en sí. Si estos han encontrado tal eco es porque responden a una necesidad que no han creado y cuyas condiciones favorables ya estaban instauradas. "Lo máximo que pueden haber hecho es agudizar y acentuar una necesidad ya creada previamente, a medida que los medios que inciden sobre ella han pasado a estar tentadoramente al alcance de todos, sin que requieran mayor esfuerzo que pulsar unas teclas" (Bauman, 2017:15).

Las personas anhelan la compañía humana, o al menos eso parece, pero en los hechos se sienten incómodos, ineptos o insatisfechos en las interacciones sociales. Entonces basta con acceder a una red para que la virtual cercanía se produzca por arte de magia: siempre a toda hora y en todo lugar es posible encontrar a alguien que responda al llamado "de entre una colección de seres solitarios" (Bauman, 20I7ः I6) 
con la sugerente garantía de que tal contacto puede romperse del mismo modo en el que se suscitó, en el instante deseado, evitando todo compromiso, disculpa o excusa.

Según Bauman hay una doble problemática con respecto a la soledad contemporánea: por una parte todos los individuos están solos aunque se encuentren en medio de la masa ahora de índole digital y virtual; por otra, la multiplicación de canales y formas para establecer interacciones inmediatas y superficiales impide a los individuos la experiencia de la soledad íntima, fecunda:

Porque cuando uno pasa a estar «siempre conectado», puede que nunca esté total y verdaderamente solo. Y si nunca está solo, entonces (por citar una vez más al profesor Zimmerman), «es menos probable que uno lea un libro por placer, dibuje, se asome a la ventana e imagine mundos distintos de los propios... Al huir de la soledad, se pierde la oportunidad de disfrutar del aislamiento, ese sublime estado en el que es posible «evocar pensamientos», sopesar, reflexionar, crear y, en definitiva, atribuir sentido y sustancia a la comunicación. Pero entonces, al no haber paladeado su sabor, uno nunca sabrá lo que se ha perdido, la ocasión que ha dejado pasar (Bauman, 2017\% 17).

En última instancia: si uno está rodeado de seres virtuales en un espacio digital masificado que garantiza la autoprotección y no exige compromisos ni consigo mismo ni con los otros, afirma Bauman, es muy poco probable que se busque establecer contacto con "la gente real del entorno inmediato": "¿Es el paraíso terrenal? -se pregunta Bauman- ¿Se cumple, por fin, el sueño? ¿Se ha resuelto la ambivalencia supuestamente inquietante de la interacción humana, reconfortante y estimulante, pero engorrosa y llena de escollos? (Bauman, 2017ः 17). Las opiniones están divididas afirma, pero "Lo que parece incuestionable, sin embargo, es que hay que pagar un precio por todo ello, un precio que puede resultar, si se piensa bien, demasiado elevado" (Bauman, 2017: 17).

\section{Hacia una conclusión crítica}

Para abordar el problema de la soledad contemporánea, el primer pensador que recuperé fue Émile Durkheim. Ciertamente, como señala Lidia Girola (2005), el concepto de anomia es uno de los que ha tenido mayores repercusiones en el pensamiento social posterior. Planteó los efectos de los “desajustes de la vida en las grandes ciudades" y forma parte de un "diagnóstico de la modernidad" (Girola, 2005: 25). El mundo actual, centrado de forma desmedida en diversas nuevas formas de 
individualidad y narcisismo, ha llevado al olvido y a la pérdida de espacios y valores públicos, compartidos, solidarios. La soledad surge del miedo al espacio abierto que se percibe amenazante y lleno de riesgo, del miedo a los otros. La soledad resguarda y purifica, pero al mismo tiempo aniquila; los sujetos se van volviendo islas.

Con el advenimiento de nuevas formas de narcisismo, con el abandono de la plaza pública y el predominio de la personalidad íntima se han postergado nuevas formas de sociabilidad y construcción de lazos:

Quizás lo más obvio sea la relación entre el vacío moral y el sentimiento de angustia existencial, para mencionarlo en términos modernos, que Durkheim menciona como componentes esenciales de la anomia y el descontento vago, el vacío interior señalados por Lasch como sentimientos subjetivos preponderantes en las sociedades contemporáneas; el hartazgo con respecto a las pautas competitivas de la cultura individualista resaltado por Maffesoli y la apatía generalizada denunciada por Lipovetsky (Girola, 269).

La construcción de una sociedad más justa asegura un espacio en el que los individuos se sientan libres y plenos para ejercer el desarrollo de su personalidad y sus expectativas y deseos, pero al mismo tiempo acompañados y protagonistas de proyectos comunes y compartidos.

Todos los pensadores que hemos recordado comparten la convicción de una soledad humana plena y necesaria que le da a los seres autosuficiencia, intimidad y libertad; pero todos reconocen esta otra, creciente, infecunda, agobiante. La que arroja a las personas, en presencia o ausencia de otros, a la zona del despojo, de la falta de solidaridad, del silencio que empobrece y el diálogo ausente. El ser humano es un ser social por esencia; solo en el contacto humano su realidad se hace plena. En este mundo vertiginoso, economizado y desechable, la conclusión en realidad solo puede formularse como pregunta, y Alain Touraine ya la hizo por nosotros: “Podremos vivir juntos?” La respuesta está en el aire.

\section{Obras citadas}

\section{Bauman, Zygmunt}

201744 cartas desde el mundo líquido, Barcelona: Paidós. 
Deleuze, Gilles

2005 "Postdata sobre las sociedades de control", en Christian Ferrer (comp.), El lenguaje libertario, Buenos Aires: Terramar Ediciones, pp. II5- I22.

Derrida, Jacques

I994 Márgenes de la filosofía, Madrid: Cátedra.

Dettano, Andrea

2013 "Cuerpos y emociones en la teoría social clásica: Georg Simmel", Adrián Scribano (comp.), Teoría social, cuerpos y emociones, Buenos Aires: Estudios Sociológicos Editora, pp. 87-100.

Durkheim, Émile 2004 El suicidio, México: Ediciones Coyoacán.

Foucault, Michel

2007 Los anormales, Buenos Aires: Fondo de Cultura Económica.

Foucault, Michel

1998 Vigilar y castigar. Nacimiento de la prisión, Méxicoः Siglo xxi Editores. Foucault, Michel I990 Tecnologías del yo y otros textos afines, Barcelona: Paidós.

Foucault, Michel

I979 Microfísica del poder, Madrid: Las Ediciones de La Piqueta.

Giddens Anthony

1998 La transformación de la intimidad. Sexualidad, amor y erotismo en las sociedades modernas, Madrid: Cátedra.

Giddens Anthony

I995 Identidad y modernidad del yo. El yo y la sociedad en la época contemporánea, Barcelona: Península.

Girola, Lidia

2005 Anomia e individualismo. Del diagnóstico de la modernidad de Durkheim

Gubern Román al pensamiento contemporáneo, México: 2005.

2000 El eros electrónico, Madrid: Taurus.

Jameson, Fredric

I99I El posmodernismo o la lógica cultural del capitalismo avanzado, Barcelona: Paidós.

Lipovetsky, Gilles

2000 La era del vacío. Ensayos sobre el individualismo contemporáneo, Barcelona: Anagrama. 
Maillard, Chantal

2001 "Metáfora", en Andrés Ortiz Osés y Patxi Lanceros (dirs.), Diccionario interdisciplinar de Hermenéutica, Bilbao: Universidad de Deusto, pp. 516-525.

Riesman, David

I964 La muchedumbre solitaria. Un estudio sobre la transformación del carácter norteamericano, Buenos Aires: Paidós.

Rizo, Marta

2006 “George Simmel, Sociabilidad e Interacción”, Cinta Moebio, 27ः pp. 43 60 , disponible en $<$ www.moebio.uchile.cl/27/rizo.html $>$.

Sibilia, Paula

2005 El hombre postorgánico. Cuerpo, subjetividad y tecnologías digitales, Buenos Aires: FCE.

Simmel, Georg

20I2 El extranjero. Sociología del extraño, Madrid: Sequitur.

Simmel, Georg

2005 "La metrópolis y la vida mental" en Bifurcaciones: Revista de Estudios Culturales Urbanos, núm. 4, disponible en $<$ https://dialnet.unirioja. es/servlet/articulo?codigo $=291664 \mathrm{I}>$.

Tamés, Enrique

2007 "Lipovetskyः del vacío a la hipermodernidad", Casa del Tiempo, octubre, pp. 47-5I. Web. 22 mayo 2018.

Touraine, Alan

2000 ¿Podremos vivir juntos?, México: FCE.

Uribe, Patricia

2010 "Los hogares unipersonales: nueva tendencia en la estructura familiar", Retos, octubre, pp. 57-68. Web. 22 may. 2018.

Lilia Leticia García Peña

Doctora en Literatura Hispánica por El Colegio de México. Miembro del Sistema Nacional de Investigadores Nivel I. Profesora investigadora de tiempo completo de la Universidad de Colima. Colabora en la Licenciatura en Letras Hispanoamericanas, la Maestría en Estudios Literarios Mexicanos y en el Doctorado en Ciencias Sociales. Su línea de investigación es el Imaginario en la literatura mexicana contemporánea. Es autora del libro Etnoliteratura. Principios teóricos para el análisis antropológico 
del imaginario simbólico-mítico (2007) y de varios artículos en revistas arbitradas e indexadas como 'Normales' y estigmatizados: los símbolos de la estigmatización social en Juan Rulfo", en Espiral, 2015, 22(64), pp.4I-66 y "La diversidad familiar en el México contemporáneo desde las narrativas literarias", en Confluenze. Rivista di studi iberoamericani, 2016, vol. 8, pp. 163 .

Citar como: Lilia Leticia García Peña (2019), "La soledad contemporánea desde la obra de pensadores esenciales: análisis y perspectivas", Iztapalapa. Revista de Ciencias Sociales y Humanidades, núm. 86, año 40, enero-junio de 2019, ISSN: 2007-9176; pp. 185-206. Disponible en <http://revistaiztapalapa. izt.uam.mx/index.php/izt/issue/archive $>$. 